\title{
DESIGN, DEVELOPMENT AND IN VITRO EVALUATION OF ERLOTINIB LOADED LIQUORICE CRUDE PROTEIN NANOPARTICLES BY BOX BEHNKEN DESIGN
}

\author{
GEETHA V. S. ${ }^{1,2}$, MALARKODI VELRAJ ${ }^{*}$ \\ ${ }^{1}$ College of Pharmaceutical Sciences, Govt. Medical College, Kozhikode, Kerala, India, ${ }^{2}$ School of Pharmaceutical Sciences, Vels Institute of \\ Science Technology and Advanced Studies (VISTAS), Vels University, Chennai, Tamil Nadu, India \\ Email: malarkodisanna@gmail.com
}

Received: 23 Mar 2021, Revised and Accepted: 28 Apr 2021

\section{ABSTRACT}

Objective: To formulate and evaluate Erlotinib loaded Liquorice crude protein (LCP) nanoparticles from the powdered liquorice root (Glycyrrhiza glabra) using Box-Behnken design.

Methods: Erlotinib loaded liquorice crude protein nanoparticles were prepared by desolvation method using ethanol-water (1:2 ratio), Tween-80 $(2 \% \mathrm{v} / \mathrm{v})$ and gluteraldehyde $(8 \% \mathrm{v} / \mathrm{v})$ as cross linking agent. Box-Behnken design with 3 factors, 3 levels and 3 responses was used to optimize the prepared nanoparticles. The independent variables were taken as A) Erlotinib concentration B) LCP concentration and C) Incubation time with responses R1) Drug entrapment efficiency R2) Drug Release and R3) Particle size. The correlation between factors and responses were studied through response surface plots and mathematical equations. The nanoparticles were evaluated for FTIR, particle size and zeta potential by Photon correlation spectroscopy (PCS) and surface morphology by TEM. The entrapment efficiency, and in vitro drug release studies in PBS pH 7.4 (26 h) were carried out. The experimental values were found to be in close resemblance with the predicted value obtained from the optimization process. The in vitro cytotoxicity studies of the prepared nanoparticles in lung cancer cell line (A 549) were studied with different concentrations for 24h.

Results: The average particle size, zeta potential, Polydispersity index (PDI) were found to be $292.1 \mathrm{~nm},-25.8 \mathrm{mV}$ and 0.384 respectively. TEM image showed that the nanoparticles dispersed well with a uniform shape and showed not much change during storage. The in vitro drug release showed $41.23 \%$ for $26 \mathrm{~h}$ in PBS (7.4) and release kinetics showed highest $\mathrm{R}^{2}$ value (0.982) for Korsmeyer-Peppas model, followed by 0.977 for Higuchi model. The in vitro cytotoxicity of prepared nanoparticles in A 549 cell line showed good results with different concentrations for $24 \mathrm{~h}$.

Conclusion: Erlotinib (Erlo) is a BCS class II drug with poor solubility, poor bioavailability and selective tyrosine kinase inhibitor for non small-cel lung cancer (NSCLC) through oral administration. To improve the oral bioavailability and absorption of molecules, plant protein as carriers is used for developing drug delivery systems due to their proven safety. The optimization variables were Conc of Erlo, Conc. of LCP and Incubation time to get responses as drug entrapment efficiency, drug release and particle size. The compatibility between drug and LCP were evaluated by FTIR.

Keywords: Erlotinib, LCP, Bioavailability, Nanoparticles, Desolvation, Drug release, Box-Behnken design, Cytotoxicity

(C) 2021 The Authors. Published by Innovare Academic Sciences Pvt Ltd. This is an open access article under the CC BY license (https://creativecommons.org/licenses/by/4.0/) DOI: https://dx.doi.org/10.22159/ijap.2021v13i4.41580. Journal homepage: https://innovareacademics.in/journals/index.php/ijap

\section{INTRODUCTION}

Erlotinib binds with adenosine triphosphate (ATP) in the epidermal growth factor receptor tyrosine kinase domain and inhibits the autophosphorylation process of tyrosine kinases [1]. This promotes cell apoptosis, inhibits angiogenesis, and prevents proliferation of cells. Thus, by designing a novel delivery system for targeted Erlo delivery, poor solubility, cell selectivity and low bioavailability can be improved [2]. The different encapsulation methods that are used as delivery systems include liposomes, polymeric-based nanoparticles [3, 4], hydrogels, and serum albumin. Among the variety of targeting ligands, hyaluronic acid (HA) and human serum albumin have proven success in lung cancer targeting with in tumour cell lines animal models [5]. Moreover a major problem associated with cancer chemotherapy $[6,7]$ is the severe side effects resulting from the normal tissue damage, irrespective of the route of administration, which can be overcome by targeted drug delivery [8, 9]. It is aimed to load this drug into a nano drug carrier system, so that it can improve poor solubility and low bioavailability, reduce rapid renal clearance and improve cell selectivity $[10,11]$. From the wide variety of proteins generally used to prepare nanoparticles and albumin from various sources (BSA, HSA, ovalbumin, plant proteins), only plant proteins are devoid of antigenicity.

Many experimental studies [12,13] reported the useful biological properties of Glycyrrhiza glabra [14] such as antioxidant, immune modulatory, anti-viral, anticancer effects and several more. Researchers have identified one kind of protein present in liquorice which can be formulated into nanoparticles $[15,16]$. Acute toxicity studies of nano formulations of Glycyrrhiza glabra extract poses no serious health hazard in Swiss albino mice [17].

\section{MATERIALS AND METHODS}

Erlotinib Hydrochloride was obtained as a gift sample from Natco Pharma Ltd. Liquorice root fine powder was obtained from Indus valley Bioorganic $(100 \%$ natural pure liquorice powder) as a gift sample. LCP was extracted, dialyzed and freeze dried to get crude protein. All other reagents were of analytical grade.

\section{Extraction of liquorice crude protein (LCP)}

Finely powdered liquorice root was extracted in phosphate buffer $(\mathrm{pH} 7.2)$ in $1: 5(\mathrm{w} / \mathrm{v})$ ratio and $100 \mathrm{Mm} \mathrm{NaCl}$ for $24 \mathrm{~h}$ at $4{ }^{\circ} \mathrm{C}$. Coarse filtration and centrifugation is done and proteins were precipitated by salting out method. Impurities were removed by changing $\mathrm{pH}$ and dialyzed to remove the excess salt for $2 \mathrm{~d}$ with intermittent changing of buffer. The dialyzed liquid was freeze dried to get crude freeze dried LCP extract, which was subjected to various further studies as follows.

\section{Quantification of proteins by lowry assay method}

Protein was estimated by Lowry assay method. The blue colour developed by the addition of Folin-ciocalteau reagent to the LCP solution and the colour developed by the biuret reaction of the protein with the alkaline cupric tartarate are measured in the Lowry method. Solubility was studied in different solvents. Fourier Transform Infrared Spectroscopy (FTIR) spectra, surface morphology (SEM) were obtained.

FTIR spectra [18], solubility and UV-calibration curve in pH 7.4 PBS of Erlotinib Hydrochloride [19] were studied. LCP-Erlotinib compatibility studies were also conducted based on FTIR spectra to study the interaction. 
Formulation of erlotinib loaded liquorice crude protein nanoparticles

Erlotinib was loaded in the ratio 1:2 (drug: crude protein) and nanoparticles were prepared by desolvation method [20-21] after adjusting the $\mathrm{pH}$ to 8 and by the addition of ethanol at a rate of $1 \mathrm{ml}$ per $\mathrm{min}$ and under magnetic stirring at $600 \mathrm{rpm}$ at room temperature with ethanol-water in ratio 1:2 using $1 \mathrm{ml}$ Tween-80 as surfactant and one drop of gluteraldehyde as cross linking agent. This is followed by ice bath sonication for fifteen minutes. The drug loaded nanoparticles were then separated by centrifugation $(10,000$ x 2 min) and lyophilized [22].

\section{Experimental design}

The Box-Behnken design using Design Expert 11.0.2 software was performed. The independent variables were A) Erlotinib Concentration (\%w/v) B) LCP Concentration (\%w/v) C) Incubation time (min) and the dependent variables were R1) Drug entrapment efficiency (\%), R2) Drug release (\%) and R3) Particle size (nm). The goal of optimization was to maximize entrapment efficiency and drug loading efficiency and to minimize particle size (table 1). Based on optimization in Box-Behnken design, contour plots and response surface plots were studied for the effects of independent variables on dependent variables with maximum desirability [23]

\section{Characterization of Erlotinib loaded LCP nanoparticles}

The particle size analysis was determined by dynamic light scattering, using a Malvern system, at a temperature $25.0 \pm 0.1{ }^{\circ} \mathrm{C}$. The zeta potential of the nanoparticles was determined using a Malvern Zetasizer at $25.0 \pm 0.1^{\circ} \mathrm{C}$. Transmission Electron Microscopy (TEM) was performed to characterize the surface morphology of the formed nanoparticles. Determination of drug entrapment efficiency (\%) was found out by using centrifugation at $15000 \mathrm{rpm}$ for $30 \mathrm{~min}$ and supernatant with free drug was measured by UV spectrophotometer at $246 \mathrm{~nm}$.

$$
\begin{aligned}
& \text { Percentage entrapment efficiency } \\
& =\frac{\text { Total amount of drug added }- \text { Amount of free drug }}{\text { Total amount of drug added }} \times 100
\end{aligned}
$$

In vitro studies of drug release from Erlo-LCP nanoparticles were carried out for $26 \mathrm{~h}$ in PBS ( $\mathrm{pH}$ 7.4) using dialysis membrane method. A sample of nanoparticles equivalent to $5 \mathrm{mg}$ of drug was dissolved in $2 \mathrm{ml}$ buffer solution and taken in a dialysis bag (Mw cutoff $10,000-12,000 \mathrm{Da}$ ) and then placed in PBS adjusted at $37 \pm 0.5$ ${ }^{\circ} \mathrm{C}$ under gentle magnetic stirring $(60 \mathrm{rpm})$ in a volume of $10 \mathrm{ml}$ achieving the sink condition. At scheduled time intervals, $2 \mathrm{ml}$ of medium was withdrawn and replaced with an equal volume of fresh medium. The samples were filtered with a membrane filter $(0.22 \mu)$ and the amount of drug released was quantified by using UV Spectrophotometer at a wavelength $246 \mathrm{~nm}$ against blank.

Release kinetics and stability studies were studied. The A 549 cell line was applied as a model cell to assay the cellular cytotoxicity of formulated Erlo-LCP nanoparticles. MTT assay method was used to assess the viability of cells.

\section{RESULTS AND DISCUSSION}

\section{Characterization of LCP extract}

Solubility: Solubility of liquorice crude protein was studied in different solvents.

\section{Estimation of protein by lowry assay method}

Total protein content of the freeze dried sample of LCP extract evaluated by Lowry assay method was found to be $94.75 \mu \mathrm{g} / \mathrm{ml}[24]$

Fourier Transform Infrared Spectroscopy (FTIR):

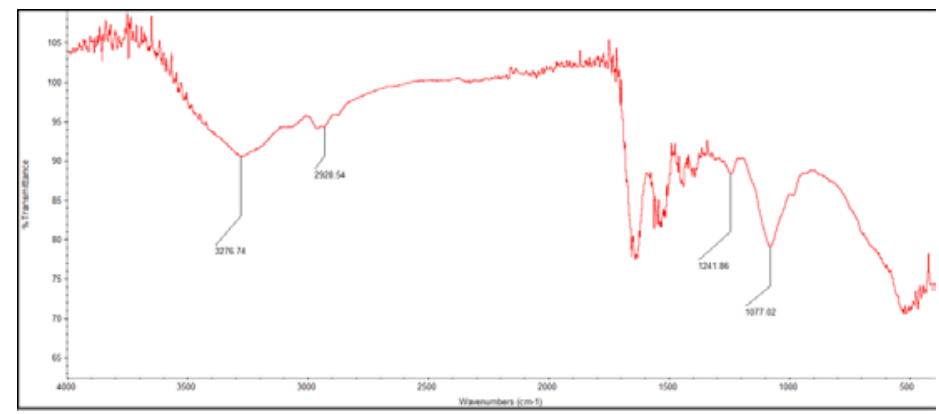

Fig. 1: FTIR spectrum of LCP extract

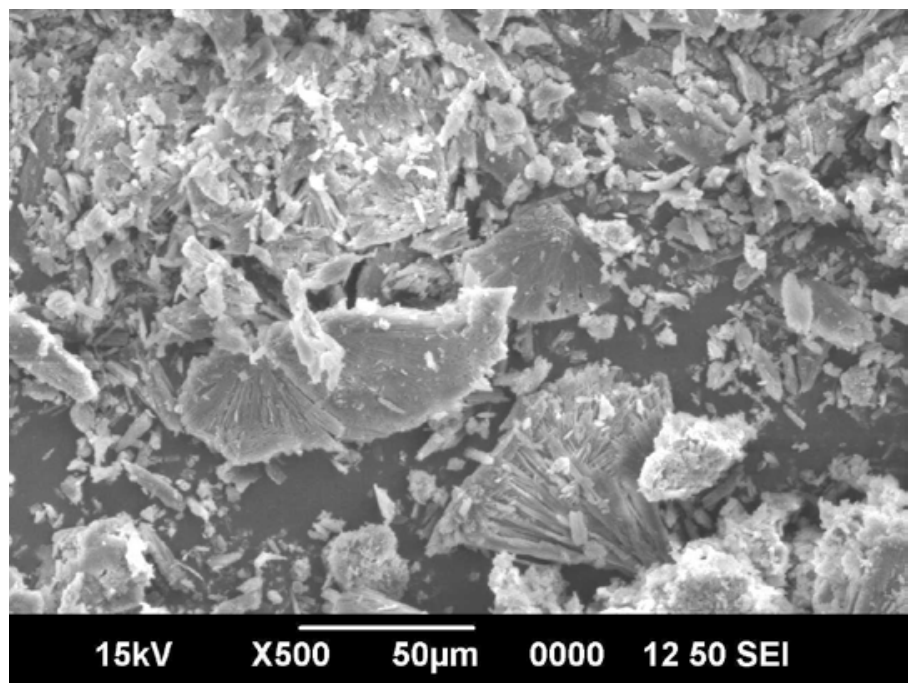

Fig. 2: SEM image of LCP extract 
Table 1: Data for FTIR spectra

\begin{tabular}{ll}
\hline Wave number $\left(\mathbf{c m}^{-1}\right)$ & Functional group \\
\hline 3276.74 & -NH Stretch. \\
2928.54 & -COOH stretch \\
1660 & $\mathrm{C}=\mathrm{O}$ bond stretching in peptide \\
1241.86 & In plane C-H bending \\
\hline
\end{tabular}

Scanning Electron Microscopy image as seen in fig, 2 shows irregular surface.

\section{Characterization of erlotinib hydrochloride}

FTIR Spectra of Erlotinib

\section{Characterization of erlotinib-LCP mixture}

FTIR spectrum of LCP-erlotinib mixture

FTIR spectra of pure Erlotinib Hydrochloride (fig. 3), LCP Extract (fig. 1) and the mixture of Erlo LCP mixture (fig. 4) are shown.

The characteristic IR absorption peaks of Erlo were all observed in the spectra of pure drug as well as Erlo-LCP mixture. This suggested that no interaction between Erlo and LCP were seen in the mixture.

\section{Optimization using box-behnken design}

Table 4 shows 3 factors, 3 responses and 3 levels based BoxBehnken design with 17 formulations which has been applied to study the effect of independent variables on dependent variables $[25,26]$.

A 3 factor 3 levels based Box-Behnken design with 17 formulations was evaluated to understand the relationship between independent variables and dependent variables (table 5)

\section{Statistical optimization by response surface methodology}

The Quadratic model was chosen as the best fit model based on regression coefficient values $\left(\mathrm{R}^{2}\right)$ very close to 1 (table 6 ) and based on $p$-values $<0.05$, which deemed the model to be significant.

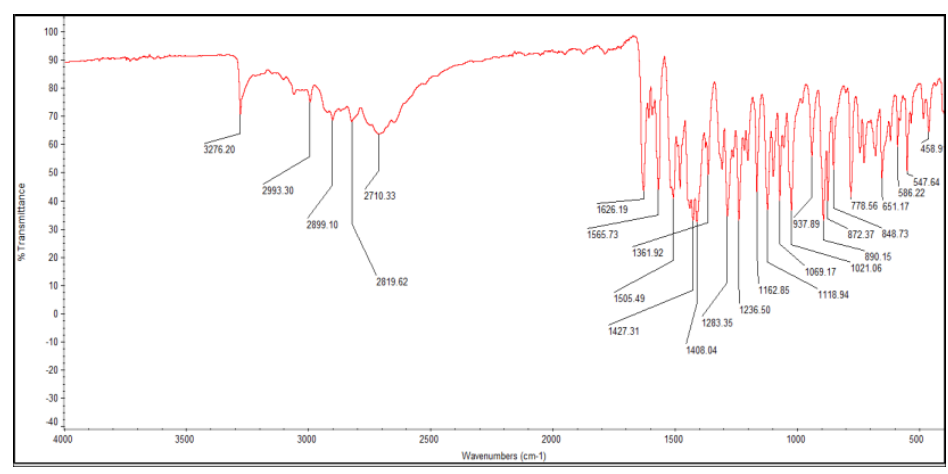

Fig. 3: FTIR spectra of erlotinib

Table 2: Data for FTIR spectra

\begin{tabular}{ll}
\hline Wave number $\left(\mathbf{c m}^{-1}\right)$ & Functional group \\
\hline 3276.2 & N-H stretch \\
1626.19 & Secondary Amine NH bend \\
1505.49 & C=C, Aromatic Ring \\
1283.35 & C=O stretch \\
\hline
\end{tabular}

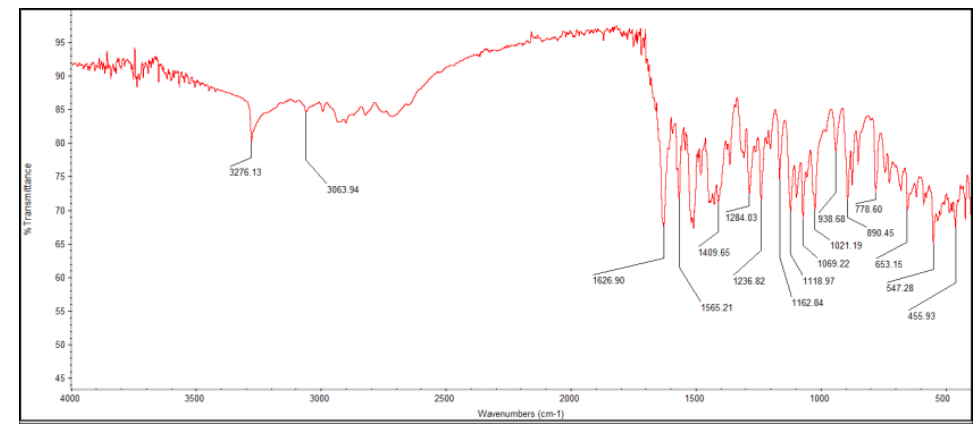

Fig. 4: FTIR spectra of Erlo-LCP mixture

Table 3: Data for FTIR spectra

\begin{tabular}{l}
\hline Wave number $\left(\mathbf{c m}^{-1}\right)$ \\
\hline 3276.13 \\
3063.94 \\
1626.9 \\
1236.82 \\
\hline
\end{tabular}

\section{Functional group}

$\mathrm{N}-\mathrm{H}$ stretch

$\mathrm{COOH}$ stretch

Secondary Amine $\mathrm{NH}$ bend

$\mathrm{NH}$ bending 
Table 4: Variables and their constraints in box-behnken design

\begin{tabular}{llll}
\hline Independent variables & Constraints & Dependent variables \\
\cline { 2 - 3 } & Lower limit & Upper limit & \\
\hline A: Erlotinib Concentration (\%w/v) & 1 & 3 & R1: Drug Entrapment Efficiency (\%) \\
B: LCP Concentration (\%w/v) & 2 & 6 & Maximise \\
C: Incubation time (hrs) & 2 & 10 & R2: Drug Release (\%) \\
\hline
\end{tabular}

Table 5: Formulations of Erlo-LCP nanoparticles

\begin{tabular}{|c|c|c|c|c|c|c|c|}
\hline & & Factor 1 & Factor 2 & Factor 3 & Response 1 & Response 2 & Response 3 \\
\hline Std & Run & A: Erlotinib Conc & B: LCP conc & C: Incubation time & Drug entrapment efficiency (DEE) & Drug release & Particle size \\
\hline & & $\% \mathrm{w} / \mathrm{v}$ & $\% \mathrm{w} / \mathrm{v}$ & hrs & $\%$ & $\%$ & nm \\
\hline 12 & 1 & 2 & 6 & 10 & $57.21 \pm 1.34$ & $26.77 \pm 2.15$ & $314.42 \pm 0.56$ \\
\hline 11 & 2 & 2 & 2 & 10 & $63.25 \pm 2.24$ & $32.73 \pm 1.54$ & $310.87 \pm 1.21$ \\
\hline 9 & 3 & 2 & 2 & 2 & $61.7 \pm 1.85$ & $28.44 \pm 0.88$ & $319.27 \pm 3.11$ \\
\hline 7 & 4 & 1 & 4 & 10 & $64.66 \pm 2.14$ & $34.48 \pm 1.37$ & $308.13 \pm 1.85$ \\
\hline 8 & 5 & 3 & 4 & 10 & $57.27 \pm 1.05$ & $25.78 \pm 1.22$ & $309.56 \pm 0.56$ \\
\hline 2 & 6 & 3 & 2 & 6 & $63.34 \pm 1.55$ & $39.68 \pm 3.19$ & $298.67 \pm 3.21$ \\
\hline 10 & 7 & 2 & 6 & 2 & $58.76 \pm 2.86$ & $23.56 \pm 2.56$ & $319.85 \pm 2.15$ \\
\hline 17 & 8 & 2 & 4 & 6 & $51.98 \pm 3.15$ & $55.58 \pm 3.44$ & $275.52 \pm 3.66$ \\
\hline 4 & 9 & 3 & 6 & 6 & $59.75 \pm 3.05$ & $33.94 \pm 1.75$ & $298.34 \pm 2.08$ \\
\hline 5 & 10 & 1 & 4 & 2 & $66.12 \pm 3.45$ & $29.23 \pm 2.01$ & $313.96 \pm 1.81$ \\
\hline 6 & 11 & 3 & 4 & 2 & $57.89 \pm 2.96$ & $22.41 \pm 2.66$ & $314.82 \pm 2.95$ \\
\hline 14 & 12 & 2 & 4 & 6 & $52.23 \pm 2.85$ & $56.67 \pm 1.28$ & $278.95 \pm 2.31$ \\
\hline 13 & 13 & 2 & 4 & 6 & $52.65 \pm 1.79$ & $52.98 \pm 1.91$ & $276.54 \pm 3.02$ \\
\hline 3 & 14 & 1 & 6 & 6 & $67.64 \pm 3.95$ & $41.46 \pm 2.36$ & $301.29 \pm 3.37$ \\
\hline-1 & 15 & 1 & 2 & 6 & $71.42 \pm 4.05$ & $46.29 \pm 2.74$ & $295.45 \pm 2.83$ \\
\hline 16 & 16 & 2 & 4 & 6 & $52.34 \pm 3.07$ & $59.65 \pm 3.02$ & $276.87 \pm 1.23$ \\
\hline 15 & 17 & 2 & 4 & 6 & $53.36 \pm 2.65$ & $56.23 \pm 1.23$ & $279.64 \pm 2.41$ \\
\hline
\end{tabular}

*Data are expressed as mean \pm SD $(n=3)$

Table 6: Fit statistics showing $\mathbf{R}^{2}$ values

\begin{tabular}{lll}
\hline Response & R $^{\mathbf{2}}$ & Adjusted R $^{\mathbf{2}}$ \\
\hline R1: Drug entrapment efficiency (\%) & 0.9965 & 0.9920 \\
R2: Drug release (\%) & 0.9914 & 0.9903 \\
R3: Particle size (nm) & 0.9968 & 0.9926 \\
\hline
\end{tabular}

The predicted $\mathrm{R}^{2}$ value of $0.9724,0.9843$ and 0.9892 were found to be in reasonable agreement with the adjusted $R^{2}$ value of 0.9920 ,
0.9903 and 0.9926 respectively. The Model F-values of 220.6, 89.26 and 240.94 implies that the model is significant.
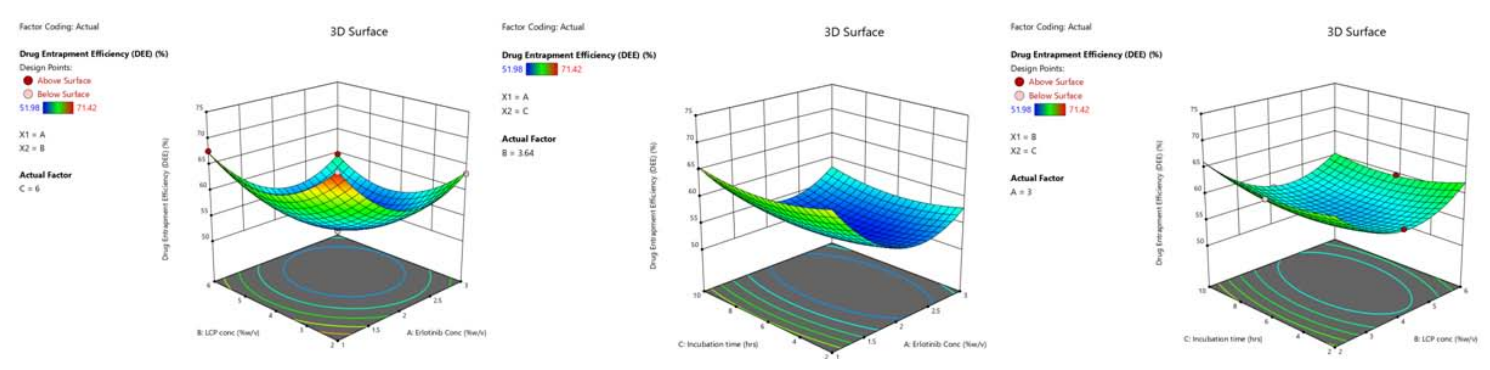

Fig. 5: 3D response surface plots between a) Erlotinib Conc, LCP Conc and drug entrapment efficiency (R1); b) Erlotinib Conc, Incubation time and drug entrapment efficiency (R1); c) LCP Conc, incubation time and drug entrapment efficiency (R1)
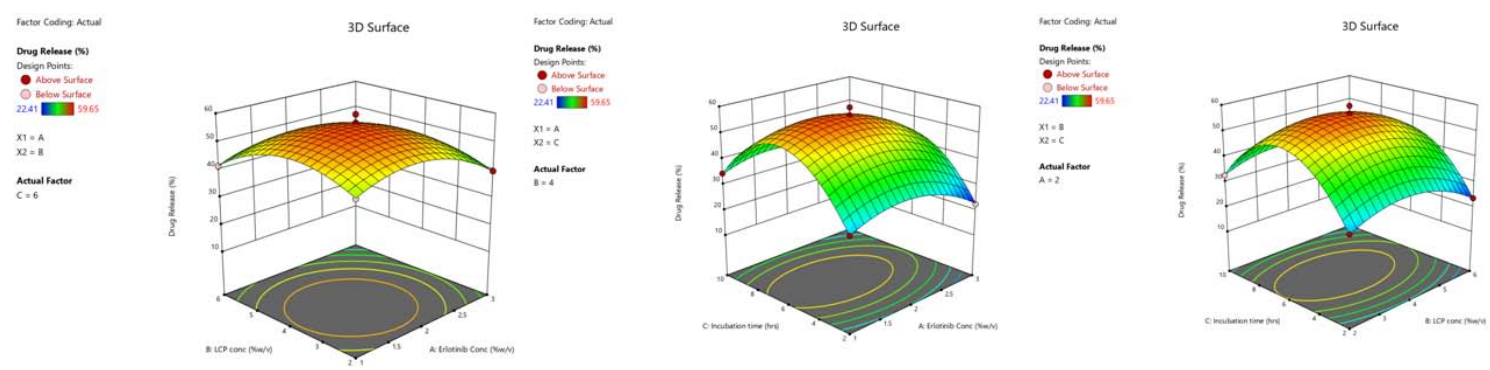

Fig. 6: 3D response surface plots between a) Erlotinib Conc, LCP Conc and Drug Release (R2); b) Erlotinib Conc, Incubation time and Drug Release (R2); c) LCP Conc, Incubation time and drug release (R2) 

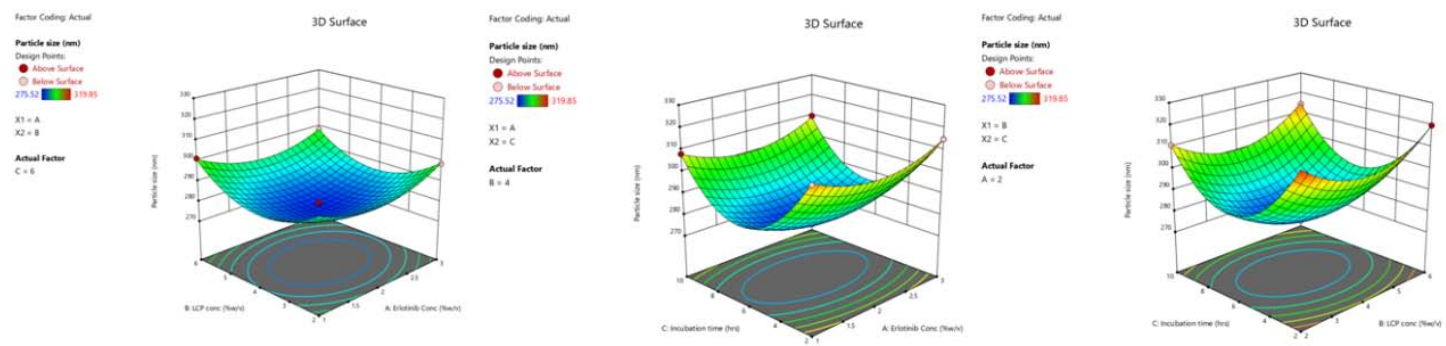

Fig. 7: 3D response surface plots between a) Erlotinib Conc, LCP Conc and Particle size (R3) b) Erlotinib Conc, Incubation time and Particle size (R3) c) LCP Conc, Incubation time and Particle size (R3)

$\mathrm{R} 1=52.512-3.94875 \mathrm{~A}-2.0475 \mathrm{~B}-0.26375 \mathrm{C}+0.0475 \mathrm{AB}+0.21 \mathrm{AC}-$ $0.7675 \mathrm{BC}+7.1365 \mathrm{~A}^{2}+5.889 \mathrm{~B}^{2}+1.8365 \mathrm{C}^{2}$

$\mathrm{R} 2=56.222-3.70625 \mathrm{~A}-2.67625 \mathrm{~B}+2.015 \mathrm{C}-0.2275 \mathrm{AB}-0.407 \mathrm{AC}-$ $0.27 \mathrm{BC}-7.88975 \mathrm{~A}^{2}-7.98975 \mathrm{~B}^{2}-20.3572 \mathrm{C}^{2}$

R3 $=277.504+0.32 \mathrm{~A}+1.205 \mathrm{~B}-3.115 \mathrm{C}-$ $1.5425 \mathrm{AB}+0.1425 \mathrm{AC}+0.7425 \mathrm{BC}+8.22425 \mathrm{~A}^{2}+12.7093 \mathrm{~B}^{2}+25.8893 \mathrm{C}^{2}$

Fig. 5a) shows the effect of Erlotinib Conc and LCP Conc on Drug Entrapment Efficiency (R1). The aim of the study was to maximize the $\mathrm{EE} \%$. R1 increases with increase in LCP Conc and Incubation time. This observation might be due to the availability of greater amount of polymers for complete encapsulation of drug. However increase in incubation time decrease the EE due to the breakup of nanoparticles due to high shear. Fig. 5b) shows the effect of Erlotinib Conc and Incubation time on R1, which increases with incubation time than with Erlo Conc. Fig. 5c) shows the effect of LCP Conc and Incubation time on $\mathrm{R} 1$, which has almost the same significant effect by both factors.
Fig. 6a) shows the effect of Erlotinib Conc and LCP Conc on Drug Release (R2). The goal of the study was to minimize the drug release to get sustained action. As shown in RSM plots drug release was decreased by increase in both the factors. This might be due to the increase in diffusion path length which minimizes the drug release as the polymer conc is increased. Fig. 6b) shows the effect of Erlotinib Conc and Incubation time on R2. Fig. 6c) shows the effect of LCP Conc and Incubation time on R2.

Fig. 7a) shows the effect of Erlotinib Conc and LCP Conc on Particle size (R3). The aim was to minimize particle size of prepared ErloLCP nanoparticles as it affects drug release. It was found that particle size was increased with increasing both drug and polymer conc and decreased with increasing incubation time due to high shear forces. Fig. 7b) shows the effect of Erlotinib Conc and Incubation time on R3. Fig. 7c) shows the effect of LCP Conc and Incubation time on R3. The predicted vs actual graphs of responses are shown in fig. 8.
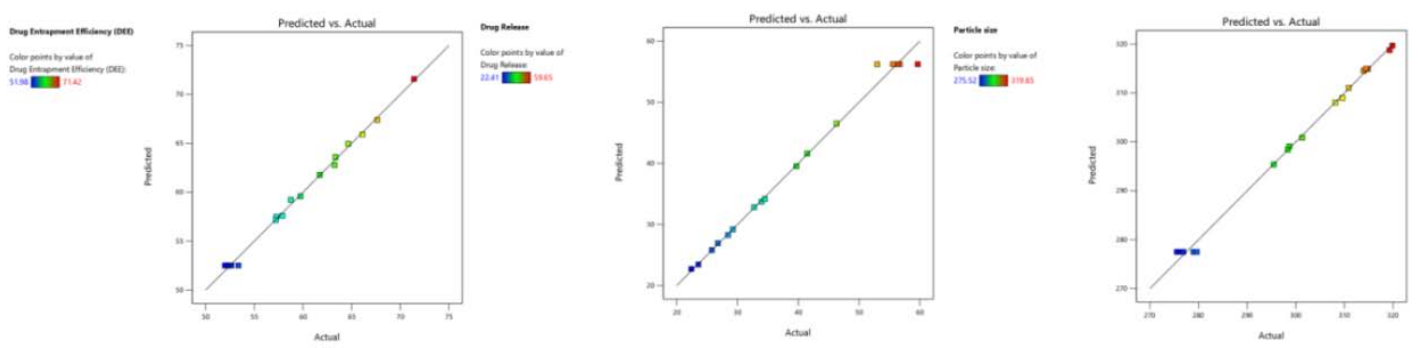

Fig. 8: Predicted vs actual graphs of a) Drug entrapment efficiency (R1); b) Drug release (R2); c) Particle size (R3)

The optimum levels of formulation factors for an optimized formulation based on the Box-Behnken design were $3 \% \mathrm{w} / \mathrm{v}$ of drug Erlotinib, $4 \% \mathrm{w} / \mathrm{v}$ of LCP, $6 \mathrm{~h}$ incubation time with predicted values of $286.04 \mathrm{~nm}$ for particle size, $55.69 \%$ for entrapment efficiency, and $44.62 \%$ for drug release.

\section{Particle size, PDI, zeta potential}

The mean particle size of nanoparticles formulation was in the range of $\mathrm{nm}$. Formulation of Erlo-LCP nanoparticles showed particle size from $275.52 \mathrm{~nm}$ to $319.85 \mathrm{~nm}$. Poly dispersivity index (PDI) of 0.384 (fig. 9) and zeta potential of-25.8mV (fig. 10) were in good range.

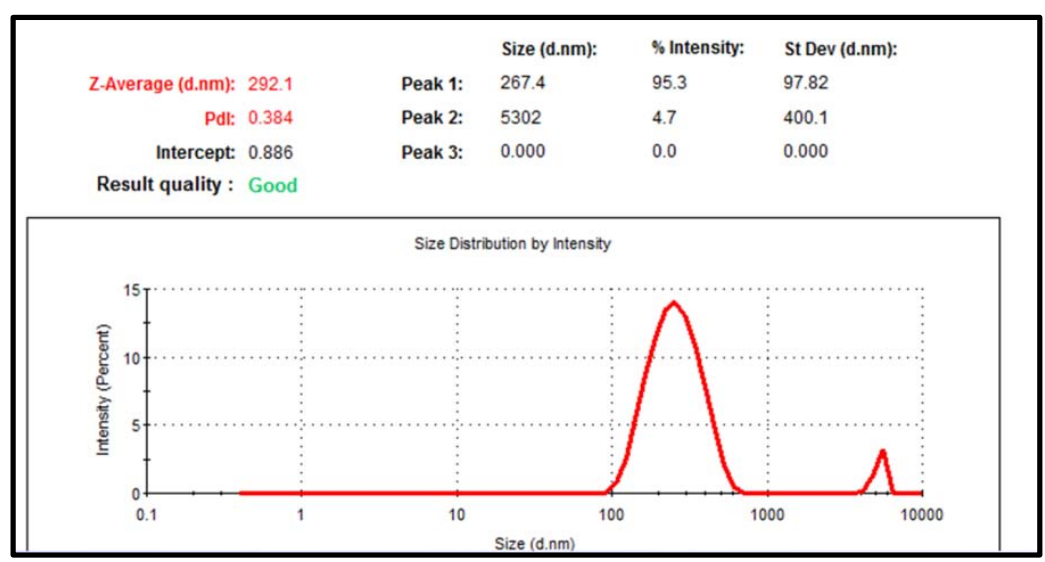

Fig. 9: Particle size analysis and polydispersity index of formulated Erlotinib loaded LCP nanoparticles 


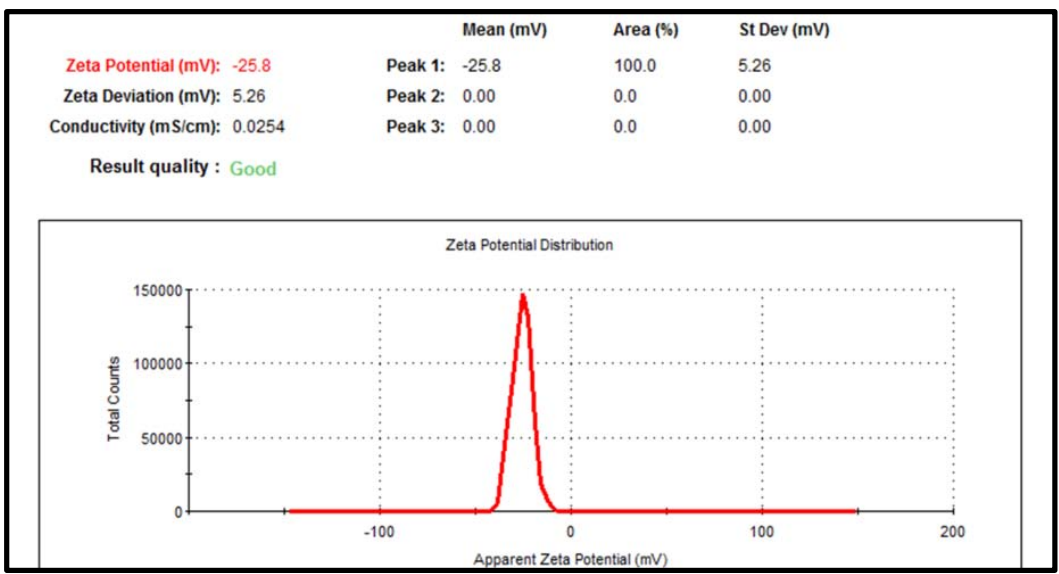

Fig. 10: Zeta potential of formulated Erlotinib loaded LCP nanoparticles

Transmission electron microscopy

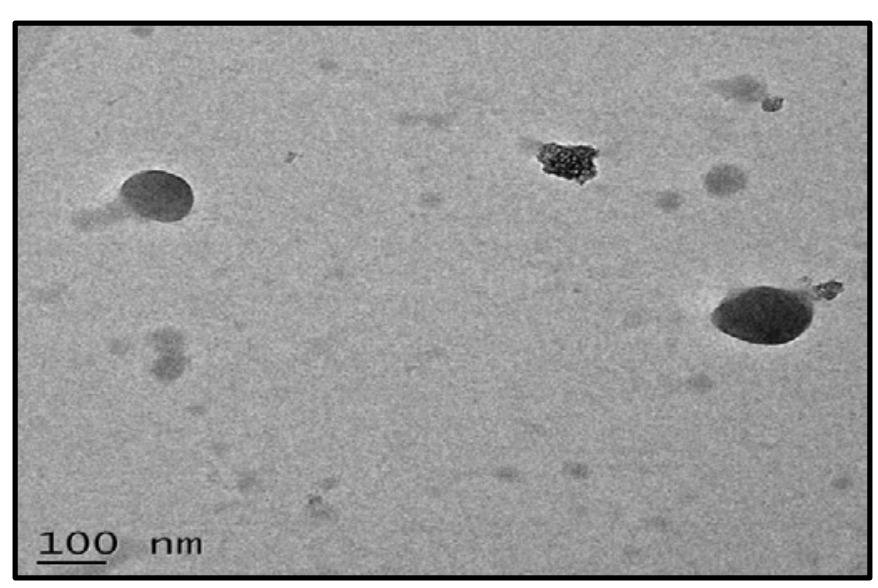

Fig. 11: TEM image of optimized nanoparticle

The TEM image (fig. 11) confirmed the uniform size distribution and spherical shape of particles.

\section{In vitro drug release from nanoparticles}

The cumulative percentage release of Erlotinib from the optimized formula after a different time period is shown as a graph (fig. 12). The release of Erlotinib follows that of sustained release without initial burst release. After 26hours, the amount of accumulated Erlotinib in PBS at pH7.4 was calculated to be $41.23 \%$ of the entrapped drug.

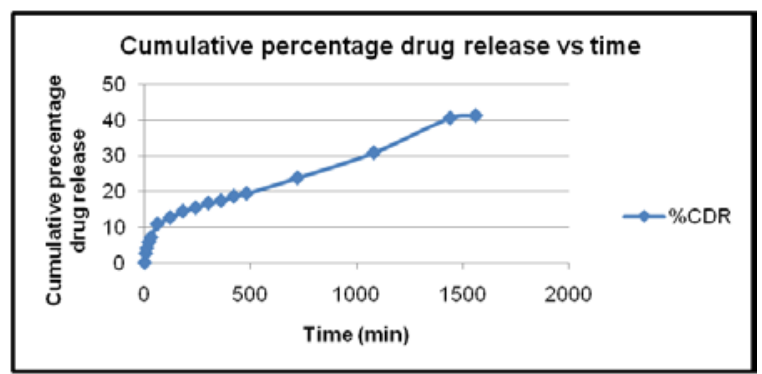

Fig. 12: Drug release profile of erlotinib from erlotinib loaded LCP nanoparticles

In vitro kinetics studies of Erlotinib-LCP nanoparticles-

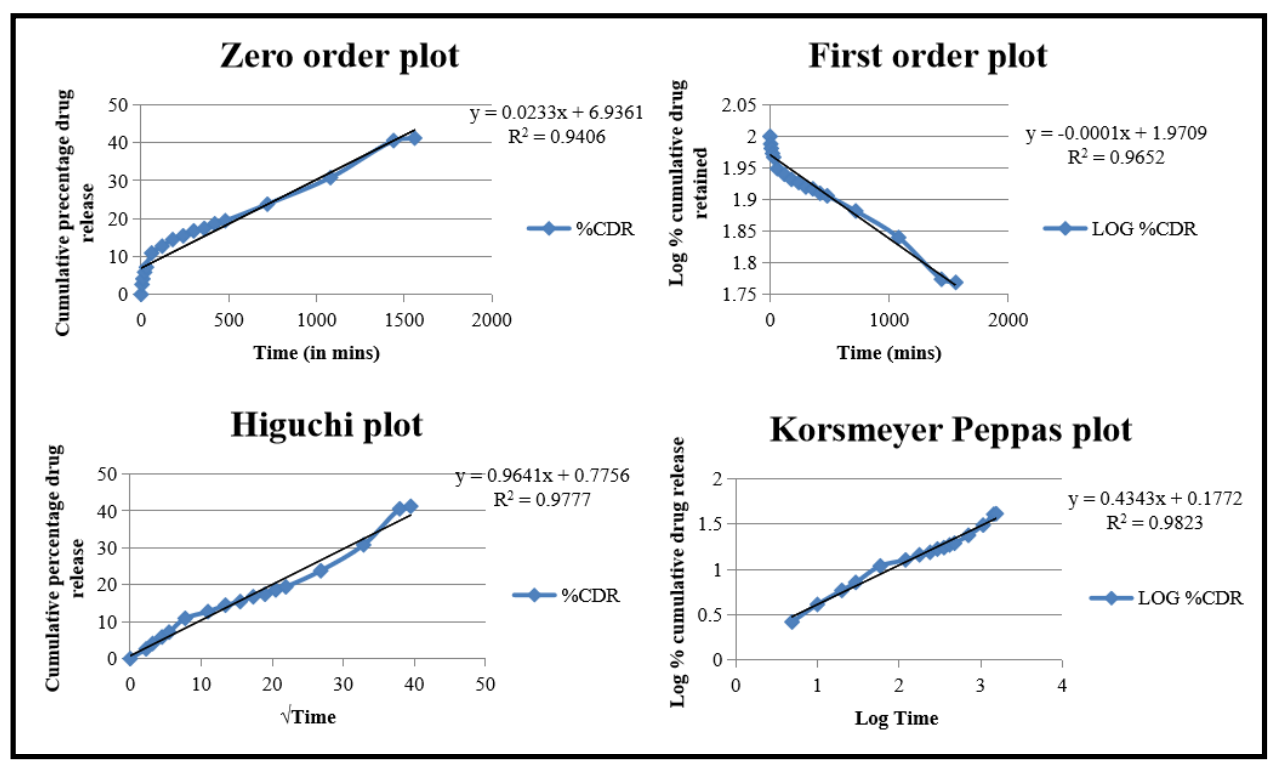

Fig. 13: In vitro drug release kinetics 
Table 7: Release kinetics

\begin{tabular}{llllll}
\hline $\mathbf{p H}$ & Zero order & First order & Higuchi & \multicolumn{2}{l}{ Korsmeyer-Peppas } \\
\cline { 2 - 5 } & $\mathbf{R}^{2}$ & $\mathbf{R}^{2}$ & $\mathbf{R}^{2}$ & $\mathbf{R}^{2}$ & $\mathbf{N}$ \\
\hline 7.4 & 0.9406 & 0.9652 & 0.9777 & 0.9823 & 0.4343 \\
\hline
\end{tabular}

\section{Lung cancer cells}

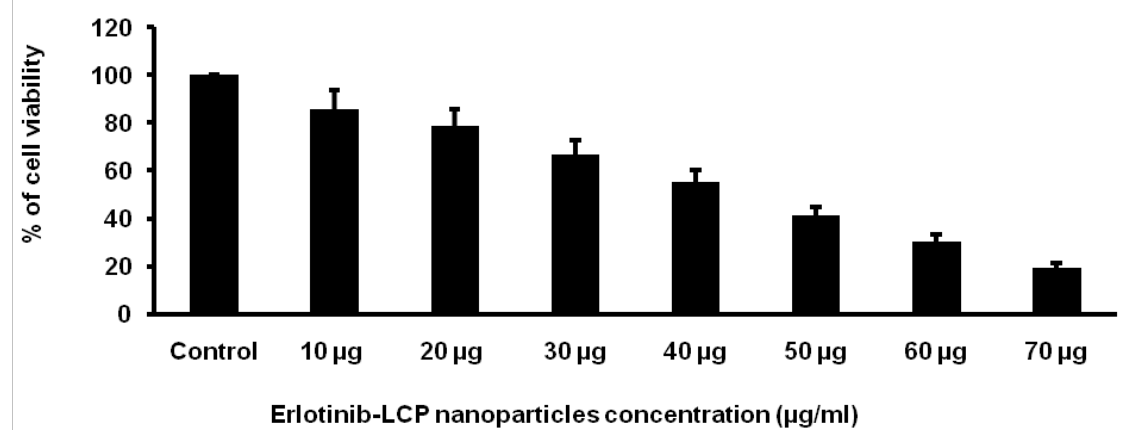

Fig. 14: Effect of formulated nanoparticles on cell viability of lung cancer cells was assessed by MTT assay, *Data are expressed as mean $\pm \operatorname{SD}(n=3)$

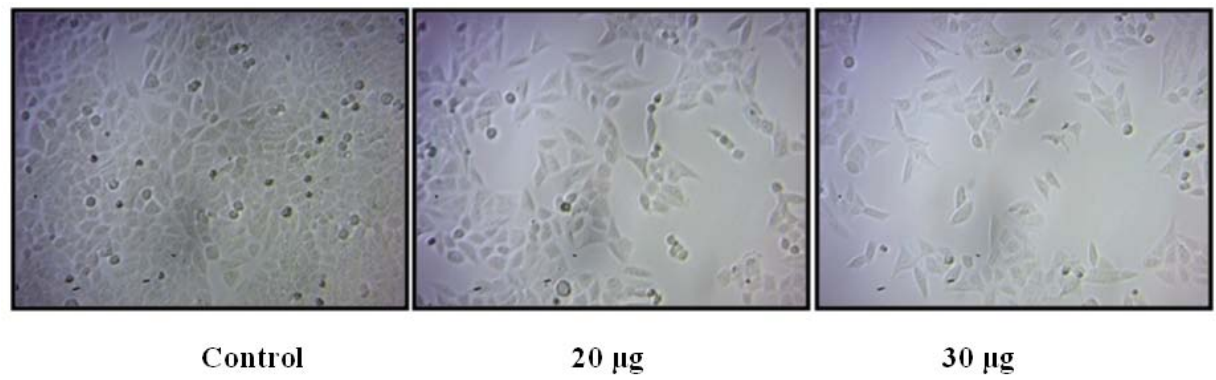

Fig. 15: Morphological changes in control and formulated nanoparticles treated lung cancer cells for $24 \mathrm{~h}$

The in vitro release of Erlotinib from the Erlo-LCP nanoparticles was studied and is shown in fig. 13. The nanoparticle formulation showed a sustained release pattern without any initial burst release, may be due to the dissolution and diffusion mechanisms the drug could be released slowly. The in vitro release kinetics studies [27] of Erlotinib from the Erlo-LCP nanoparticles in PBS (pH 7.4) fits well with Korsmeyer-Peppas model with $\mathrm{R}^{2}$ value 0.9823 (table 7).

\section{Stability studies}

The optimized Erlo-LCP nanoparticles were stored at $4{ }^{\circ} \mathrm{C}$ (which is ideal for protein) for $6 \mathrm{~m}$ showed no remarkable changes in particle size, zeta potential and drug content.

\section{In vitro cytotoxicity studies}

Cell viability assay, A549 viable cells were harvested and counted using hemocytometer diluted in DMEM medium to a density of $1 \times 10^{4}$ cells/ml was seeded in 96 well plates for each well and incubated for $24 \mathrm{~h}$ to allow attachment. The A549 cells were treated with increasing concentration of erlotinib $(10-70 \mu \mathrm{g} / \mathrm{ml})$ for $24 \mathrm{~h}$ and the results are expressed as a percentage of the control value in presenting as a cell cytotoxicity ratio for lung cancer cells using MTT assay [28]

Photomicrograph (40x) represents morphological changes in lung cancer cells such as shrinkage, detachment, membrane blebbing and distorted shape induced by erlotinib treatment $(20$ and $30 \mu \mathrm{g} / \mathrm{ml}$ for $24 \mathrm{~h}$ ) as compared with control. Control cells showed normal intact cell morphology and their images were captured by light microscope.

\section{CONCLUSION}

The present study aimed to extract the liquorice root crude protein by salting out method, followed by centrifugation and dialysis.
Formulation of nanoparticles by cost effective desolvation technique was performed followed by optimization by Box-Behnken Design. The results showed that Erlotinib Conc, LCP Conc and Incubation time had a significant effect on drug entrapment efficiency (\%), drug release $(\%)$ and particle size $(\mathrm{nm})$. FTIR Spectroscopy and TEM were studied and revealed the formation of drug loaded nanoparticles as spherical structures with definite borders. The in vitro drug release and their kinetics were also evaluated and showed drug release pattern as that of Korsemeyer-Peppas model $\left(\mathrm{R}^{2}\right.$ 0.9823). Stability studies conducted at $4{ }^{\circ} \mathrm{C}$ for 6 mo confirms the physical and chemical stability of the formulation. MTT assay on A 549 lung cancer cell showed comparable in vitro cytotoxicity of the prepared formulation with IC50 value as $35.50 \mu \mathrm{g}$. The cellular cytotoxicity of Erlo-LCP nanoparticles increased significantly under the same incubation condition which may due to the fact that the increase in intracellular drug concentration is by the transportation of nanoparticles with the aid of LCP as carrier. Shen and Li studied the effect of HA/HSA co-modified erlotinib albumin nanoparticles for lung cancer treatment. The overall results of this study indicate that there is a reasonable potential for nano particulate delivery of Erlotinib along with natural LCP (as carrier) in minimizing drug induced toxicity and resistance.

\section{ACKNOWLEDGEMENT}

The authors would like to acknowledge the College of Pharmaceutical Sciences, Govt. Medical College, Thiruvananthapuram, Kerala, India and University of Kerala, Trivandrum, Kerala for their technical support.

\section{FUNDING}




\section{AUTHORS CONTRIBUTIONS}

All the authors have contributed equally.

\section{CONFLICT OF INTERESTS}

The authors declare that they have no conflict of interest.

\section{REFERENCES}

1. Barghi L, Asgari D, Barar J, Nakhlband A, Valizadeh H. Synthesis, characterization and in vitro anti-tumoral evaluation of Erlotinib-PCEC nanoparticles. Asian Pac J Cancer Prev 2014;15:10281-7.

2. Dora CP, Trotta F, Kushwah V, Devasari N, Singh C, Suresh S, Jain S. Potential of erlotinib cyclodextrin nanosponge complex to enhance solubility, dissolution rate, in vitro cytotoxicity and oral bioavailability. Carbohydr Polym 2016;137:339-49.

3. Bhambere D, Shirivastava B, Sharma P, Gide P. Effect of Polymer and Formulation Variables on Properties of SelfAssembled Polymeric Micellar Nanoparticles. J Nanomedicine Biotherapeutic Discov 2014;4:129.

4. Bhatia Saurabh. Nanoparticles Types, Classification, Characterization, Fabrication Methods And Drug Delivery Applications. Natural Polymer Drug Delivery Systems 2016;33-93.

5. Shen Y, Li W. HA/HSA co-modified erlotinib-albumin nanoparticles for lung cancer treatment. Drug Des Devel Ther 2018;12:2285-92.

6. Kim ST, Lee J, Kim JH, Won YW, Sun JM, Yun J, Park YH, Ahn JS, Park K, Ahn MJ. Comparison of gefitinib versus erlotinib in patients with nonsmall cell lung cancer who failed previous chemotherapy. Cancer 2010;116:3025-33.

7. Sechler M, Cizmic AD, Avasarala S, Van Scoyk M, Brzezinski C, Kelley N, Bikkavilli RK, Winn RA. Non-small-cell lung cancer: molecular targeted therapy and personalized medicine-drug resistance, mechanisms, and strategies. Pharmgenomics Pers Med 2013;6:25-36.

8. Coban, Ö., Değim, Z. Development of Nanocochleates Containing Erlotinib $\mathrm{HCl}$ and Dexketoprofen Trometamol and Evaluation of In vitro Characteristic Properties. Turkish journal of pharmaceutical sciences 2018;15:16-21.

9. Zhou X, Tao H, Shi KH. Development of a nanoliposomal formulation of erlotinib for lung cancer and in vitro/in vivo antitumoral evaluation. Drug Des Devel Ther 2017;12:1-8.

10. Truong DH, Tran TH, Ramasamy T, Choi JY, Lee HH, Moon C, Choi HG, Yong CS, Kim JO. Development of solid selfemulsifying formulation for improving the oral bioavailability of erlotinib. Aaps Pharmscitech 2016;17:466-73.

11. Mandal B, Mittal NK, Balabathula P, Thoma LA, Wood GC. Development and in vitro evaluation of core-shell type lipidpolymer hybrid nanoparticles for the delivery of erlotinib in non-small cell lung cancer. Eur J Pharm Sci 2016;81:162-71.

12. Ajazuddin, Saraf S. Applications of novel drug delivery system for herbal formulations. Fitoterapia 2010;81:680-9.

13. Thakur D, Abhilasha, Jain A, Ghoshal G. Evaluation of Phytochemical, Antioxidant and Antimicrobial Properties of Glycyrrhizin Extracted from Roots of Glycyrrhiza Glabra. Journal of Scientific and Industrial Research 2016;75:487-94.
14. Shi L, Tang C, Yin C. Glycyrrhizin-modified O-carboxymethyl chitosan nanoparticles as drug vehicles targeting hepatocellular carcinoma. Biomaterials 2012;33:7594-604.

15. Ke, L. J., Gao, G. Z., Shen, Y., Zhou, J. W., and Rao, P. F. Encapsulation of Aconitine in Self-Assembled Licorice Protein Nanoparticles Reduces the Toxicity In vivo. Nanoscale research letters 2015;10:449.

16. Kim B, Seo B, Park S, Lee C, Kim JO, Oh KT, Lee ES, Choi HG, Youn YS. Albumin nanoparticles with synergistic antitumor efficacy against metastatic lung cancers. Colloids Surf B Biointerfaces 2017;158:157-66.

17. Mukne Alka Pravin, Viswanathan Vivek, Pharande Rajesh Raghunath, Bannalikar Anilkumar Sadashivrao. Acute toxicity studies of nano-formulations of glycyrrhiza glabra extract in swiss albino mice. World J Pharm Pharm Sci 2017;6:820-9.

18. Saravanan VS, Rao BM. Analytical Method Development and Validation for the Determination of Erlotinib Hydrochloride Bulk and in Pharmaceutical Dosage Form. Journal of Drug Delivery and Therapeutics 2013;3:703-9.

19. M. Mathrusri Annapurna, B. Venkatesh and R. Krishna Chaitanya. Analytical Techniques for the Determination of Erlotinib $\mathrm{HCl}$ in Pharmaceutical Dosage Forms by Spectrophotometry. Chem Sci Trans 2014;3:840-6.

20. Jahanban-Esfahlan A, Dastmalchi S, Davaran S. A simple improved desolvation method for the rapid preparation of albumin nanoparticles. Int J Biol Macromol 2021;91:703-9.

21. Sravya Nella, Kiran Babu Uppuluri. Formulation and In vitro Evaluation of Piroxicam Loaded BSA Nanospheres by Desolvation, J Nanomed Nanotechnol 2015;6.

22. Yang KM, Shin IC, Park JW, Kim KS, Kim DK, Park K, Kim K. Nanoparticulation improves bioavailability of Erlotinib. Drug Dev Ind Pharm 2017;43:1557-65.

23. Vrignaud S, Hureaux J, Wack S, Benoit JP, Saulnier P. Design, optimization and in vitro evaluation of reverse micelle-loaded lipid nanocarriers containing erlotinib hydrochloride. Int J Pharm 2012;436:194-200.

24. Geetha V. S, Malarkodi Velraj. Formulation, Optimization And In vitro Evaluation of 5-Fluorouracil Loaded Liquorice Crude Protein Nanoparticles For Sustained Drug Delivery Using Boxbehnken Design. Int J App Pharm. 2021;13:216-26.

25. Naveen Gupta, Shailesh Jain. Designing And Optimization Of Naproxen Sodium Deformable Vesicular Systems Through Factorial Design: Box Behenken Model. Int J App Pharm. 2021;13:190-7.

26. Novalinab. R. Purba, Abdul Rohman, Sudibyo Martono. The Optimization Of HPLC For Quantitative Analysis of Acid Orange 7 Andsudan Ii In Cosmetic Products Using Box Behnken Design. Int J App Pharm. 2021;11:130-7.

27. Dash S, Murthy PN, Nath L, Chowdhury P. Kinetic modeling on drug release from controlled drug delivery systems. Acta Pol Pharm 2010;67:217-23.

28. Ashwini S Shinde, Vijay D Mendhulkar. Antiproliferative Activity of Elephantopus Scaber Mediated Silver Nanoparticles against MCF-7, A-549, SCC-40, and COLO-205 human cancer cell lines. Asian J Pharm Clin Res. 2020;13:163-7. 